\title{
REVIEW \\ Second-Generation Polymeric Precursors for BN and SiNCB Ceramic Materials
}

\author{
Thomas Wideman, ${ }^{1}$ Paul J. Fazen, ${ }^{1}$ Kai Su, ${ }^{1,2}$ Edward E. Remsen, ${ }^{3}$ \\ Gregg A. Zank ${ }^{2}$ and Larry G. Sneddon ${ }^{1 *}$ \\ ${ }^{1}$ Department of Chemistry and Laboratory for the Research on the Structure of Matter, University of \\ Pennsylvania, Philadelphia, PA 19104-6323, USA \\ ${ }^{2}$ The Advanced Ceramics Program, Dow Corning Corporation, Midland, MI 48686-0995, USA \\ ${ }^{3}$ Analytical Sciences Center, Monsanto Corporate Research, Monsanto Company, 800 North Lindbergh \\ Blvd, St Louis, MO 63167, USA
}

\begin{abstract}
Our recent work directed at the design, synthesis, characterization and applications of new types of polyborazylene and polyborosilazane polymers is reviewed with a focus on the use of these polymers as processable precursors to $\mathrm{BN}$ and SiNCB composites. A design strategy based on the controlled functionalization of preformed polymers with pendant groups of suitable compositions and crosslinking properties has been employed to yield second-generation dipentylamine-polyborazylene (DPA) and pinacolborane-hydridopolysilazane (PIN-HPZ) polymers, which, unlike the parent polyborazylene $(\mathrm{PB})$ and the borazine-hydridopolysilazane (B-HPZ) polymers, are stable as melts and can be easily melt-spun into polymer fibers. Subsequent pyrolyses of these polymer fibers then provide excellent routes to $\mathrm{BN}$ and SiNCB ceramic fibers. (C) 1998 John Wiley \& Sons, Ltd.
\end{abstract}

Keywords: ceramics; preceramic polymers; SiNCB composites; boron nitride; boron; silicon

Received 30 May 1997; accepted 7 July 1997

The development of efficient methods for the production of complex structural and electronic materials in usable forms is one of the most

* Correspondence to: Larry G. Sneddon, Department of Chemistry and Laboratory for the Research on the Structure of Matter, University of Pennsylvania, Philadelphia, PA 19104-6323, USA. Contract/grant sponsor: US Department of Energy, Division of Chemical Sciences, US Office of Basic Energy Sciences, US Office of Energy Research.

Contract/grant sponsor: US National Science Foundation. important problems of modern solid-state chemistry and materials science. The polymeric precursor approach, in which a polymer is first formed into the desired shape and then decomposed to the final ceramic material with retention of this shape, has been shown to be an important new route for producing many ceramics in processed forms. ${ }^{1}$ However, the design of new inorganic precursor polymers with the required composition and appropriate chemical and physical properties remains a formidable scientific challenge. In this paper, we review our recent work directed at the design, synthesis, characterization and applications of new types of polyborazylene and polyborosilazane polymers, with a focus on the use of these polymers as processable precursors to $\mathrm{BN}$ and SiNCB composites.

\section{HYBRID POLYBORAZYLENE PRECURSORS TO BORON NITRIDE}

Boron nitride has a wide range of attractive properties, including high-temperature stability and strength, a low dielectric constant, large thermal conductivity, hardness and corrosion and oxidation resistance, leading to a number of potential applications as a structural or electronic material. ${ }^{2-6}$ Boron nitride powders may be easily obtained, ${ }^{7}$ but it has proven more difficult to prepare $\mathrm{BN}$ in more complex forms, especially fibers and coatings. Thus, there has been intense interest by many research groups on the development of polymeric precursors to $\mathrm{BN}^{2}$

We have previously shown that borazine can be readily dehydropolymerized to give a soluble 
polymer, polyborazylene (PB), in excellent yields (Eqn [1]). 8,9

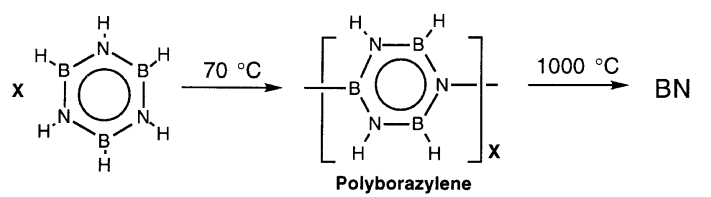

The combined analytical, spectroscopic and molecular-weight data indicate that the borazine ring structure is retained in the polymer. The polymer has also been shown to have a complex structure, related to those of the organic polyphenylenes, having linear, branched-chain and fusedcyclic segments with typical $M_{\mathrm{n}}=500-900 \mathrm{~g}$ $\mathrm{mol}^{-1}$ and $M_{\mathrm{w}}=3000-8000 \mathrm{~g} \mathrm{~mol}^{-1}$ Furthermore, according to its powder X-ray diffraction spectra, the polymer appears to have a layered structure in the solid state.

Pyrolysis studies show that polyborazylene is converted to boron nitride in excellent chemical (89-99\%) and ceramic (84-93\%) yields. Studies of the polymer-to-ceramic conversion suggest a process involving a two-dimensional crosslinking reaction similar to that shown in Scheme 1.

While polyborazylene has proven to be an excellent precursor for the production of boron nitride coatings, films and shaped materials, the crosslinking reaction depicted in Scheme 1 occurs at low temperature and has prevented applications of the polymer requiring melt-processing. Thus, the key to other more demanding applications of the polyborazylene polymer, such as in the meltspinning of fibers, is to control the dehydrocoupling reaction that leads to the formation of boron- nitrogen crosslinks between the polymer chains. One strategy by which this could be accomplished is to reduce the number of reactive $\mathrm{B}-\mathrm{H}$ or $\mathrm{N}-\mathrm{H}$ sites by functionalizing the polymer with suitable substituents. In this way it should be possible to improve the processability of polyborazylene both by increasing the thermal stability of the polymer and by lowering its glass transition temperature $\left(T_{g}\right)$. With these aims in mind, we have investigated two new types of 'second-generation' polyborazylenes: (1) polyorganoborazylenes ${ }^{10}$ and (2) aminefunctionalized polyborazylenes.

\section{Polyorganoborazylenes ${ }^{10}$}

$B$-Alkylpolyborazylenes have now been synthesized by two different methods. First, $B$-alkylborazines, which can be readily obtained by the transition-metal-catalyzed hydroboration of borazine with olefins (Eqn [2]), ${ }^{10}$ have been thermally polymerized, as shown in Eqn [3].

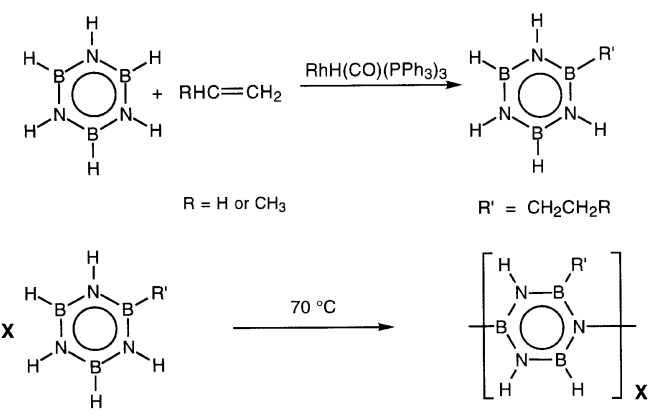

$B$-Alkylborazines require longer thermal polymerization reaction times than the parent com-

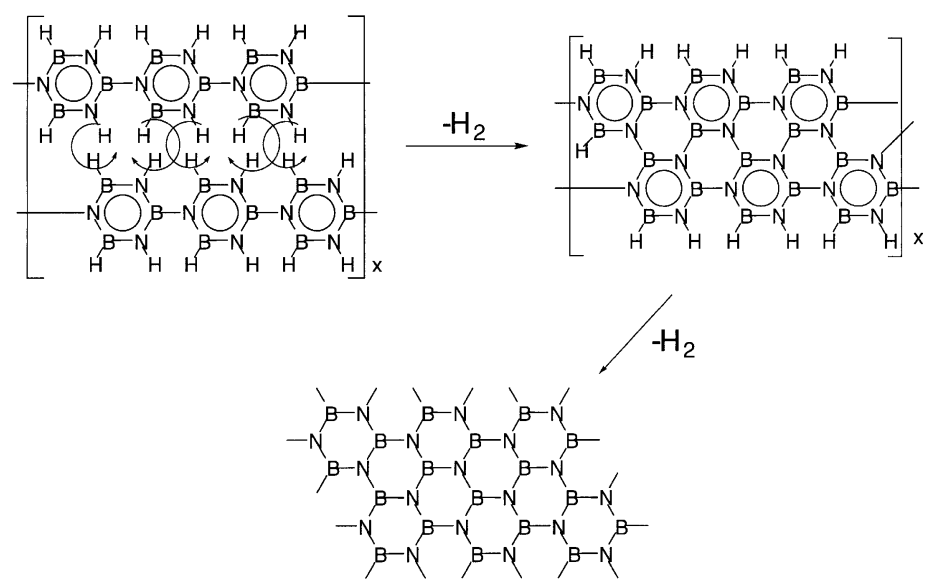

Scheme 1 Proposed two-dimensional crosslinking process for the ceramic conversion reaction of polyborazylene. 
pound. For example, samples of $B$-ethyl- and $B$ propyl-borazine were heated at $70^{\circ} \mathrm{C}$ for weeks without showing the change in viscosity or hydrogen evolution which occurs within $48 \mathrm{~h}$ with borazine. After heating for one month, molecularweight studies of the polymerized $B$-alkylborazines indicated that these polymers have $M_{\mathrm{n}}$ values similar to the parent polymer $\left(M_{\mathrm{n}}=540\right.$ for polyethylborazylene and $M_{\mathrm{n}}=468$ for polypropylborazylene). However, $M_{\mathrm{w}}$ is considerably less than the parent polymer $\left(M_{\mathrm{w}}=926\right.$ for polyethylborazylene and $M_{\mathrm{w}}=824$ for polypropylborazylene). This is consistent with a decrease in crosslinking and chain branching, as would be expected given that one of the borazinyl B-H groups has been removed.

The second method by which $B$-alkylpolyborazylene polymers have been produced is by the modification of the preformed polyborazylene backbone. Thus, the $\mathrm{RhH}(\mathrm{CO})\left(\mathrm{PPh}_{3}\right)_{3}$-catalyzed hydroboration of olefins by polyborazylene (Eqn [4]), produces poly- $B$-alkylborazines in excellent yields.

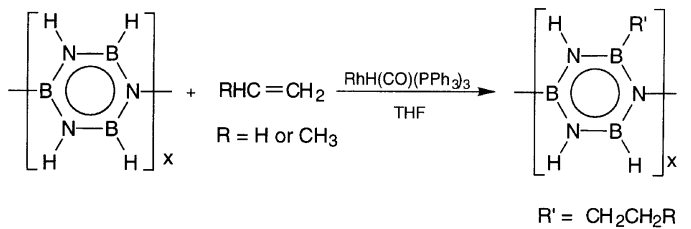

The degree of alkylation can be controlled, from an average of less than one alkyl group per every two rings for the propyl-substituted polymer, $\mathrm{B}_{3} \mathrm{~N}_{3} \mathrm{H}_{3}\left(\mathrm{C}_{3} \mathrm{H}_{7}\right)_{0.4}$, to almost one alkyl group for every borazine ring in the ethyl-substituted polymer, $\mathrm{B}_{3} \mathrm{~N}_{3.2} \mathrm{H}_{2.4}\left(\mathrm{C}_{2} \mathrm{H}_{5}\right)_{0.9}$. Molecular-weight studies showed increased molecular weights $M_{\mathrm{n}}=$ 1349) compared with the crude starting polymer $\left(M_{\mathrm{n}}=506\right)$, with incorporation of ethyl groups into the polymer. Density measurements indicated that these polymers are less dense $\left(1.42 \mathrm{~g} \mathrm{ml}^{-1}\right)$ than the parent polymer $\left(1.56 \mathrm{~g} \mathrm{ml}^{-1}\right.$, suggesting that the alkyl substituents increased interchain distances.

Studies of the ceramic conversion reactions of these new $B$-alkylated polyborazylenes have demonstrated that the thermally-induced crosslinking reactions are reduced compared to those of the polyborazylene polymer. TGA studies of the two polymers under argon show the onset of their initial weight losses are at higher temperatures than the parent polymer, suggesting the alkyl groups do, in fact, inhibit interchain dehydrocoupling. Both polymers, however, show larger weight losses during pyrolysis than does polyborazylene. Pre- dicted ceramic yields based on loss of only the alkyl groups and hydrogen would be $72 \%$ for the ethyl polymer and $63 \%$ for the propyl polymer, but both polymers showed ceramic yields near $50 \%$. The lower yields are probably attributable to volatilization of lower-molecular-weight species. Indeed, TGA-MS studies of these polymers have shown, in addition to the loss of hydrogen and hydrocarbons, the loss of some alkylborazine species. In the final stages of the ceramic conversion both polymers appear to lose only hydrogen.

\section{Amine Modified Polyborazylenes $^{11,12}$}

While the polyorganoborazylenes described above showed a decrease in the degree of low-temperature crosslinking reactions, the $T_{\mathrm{g}}$ of the polymers could not be reduced below the onset of crosslinking. Thus, these polymers are not meltable. Furthermore, because of inefficient elimination of the alkyl groups during pyrolysis, high carbon contents (2.0 $6.5 \%$ ) were found in the ceramics derived from both synthetic routes. Therefore, a second approach for the formation of hybrid polyborazylenes was initiated.

Previous work by Kimura and coworkers ${ }^{13-15}$ has shown that processable BN polymer precursors can be obtained from the reaction of $B$-trimethylaminoborazine with laurylamine [Eqn [5]). The long-chain alkylamine groups improved the plasticity of the polymers, allowing them to be meltspun. Furthermore, the amines could be eliminated easily during pyrolysis, by transamination reactions to produce low carbon contents. Pyrolysis of the polymer fibers under ammonia further served to remove carbon from the materials, yielding $10 \mu \mathrm{m}$ BN ceramic fibers of excellent quality, with tensile strengths of $\mathrm{ca} 1 \mathrm{GPa}$ and elastic moduli of $78 \mathrm{GPa} .{ }^{13-15}$

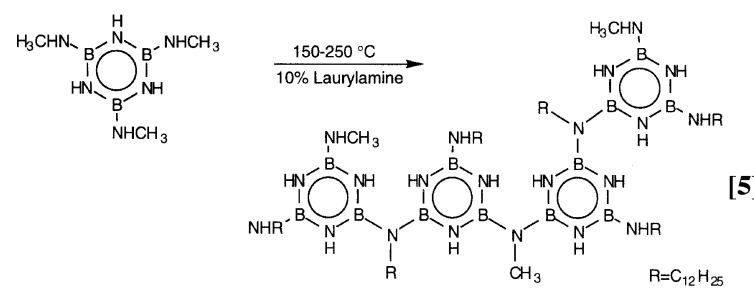

Using a similar approach, we have now found that new amine-modified polyborazylenes, containing amino groups pendant to the polymer backbone, can be obtained readily by the reaction of polyborazylene with secondary amines, including 
Table 1 Synthesis and composition of amine-modified polyborazylenes

\begin{tabular}{|c|c|c|c|}
\hline Polymer & $\begin{array}{l}\text { PB/Amine/Glyme } \\
\text { (g:ml:ml) }\end{array}$ & $\begin{array}{c}\text { Time } \\
\text { at } 75^{\circ} \mathrm{C}(\mathrm{h})\end{array}$ & Composition \\
\hline $\mathrm{PB}$ & - & - & $\left(\mathrm{B}_{3.0} \mathrm{~N}_{3.2} \mathrm{H}_{3.6}\right)$ \\
\hline DPA-1 & $5.02: 20: 20$ & 1 & $\left(\mathrm{~B}_{3.0} \mathrm{~N}_{3.6} \mathrm{H}_{3.7}\right)\left(\mathrm{NPn}_{2}\right)_{0.16}$ \\
\hline DPA-2 & $4.97: 20: 20$ & 15 & $\left(\mathrm{~B}_{3.0} \mathrm{~N}_{3.0} \mathrm{H}_{3.5}\right)\left(\mathrm{NPn}_{2}\right)_{0.23}$ \\
\hline DPA-3 & $5.03: 20: 20$ & 120 & $\left(\mathrm{~B}_{3.0} \mathrm{~N}_{3.0} \mathrm{H}_{3.3}\right)\left(\mathrm{NPn}_{2}\right)_{0.33}$ \\
\hline DPA-4 & $2.55: 25: 25$ & 192 & $\left(\mathrm{~B}_{3.0} \mathrm{~N}_{3.12} \mathrm{H}_{3.9}\right)\left(\mathrm{NPn}_{2}\right)_{0.47}$ \\
\hline DEA & 4.98:40:0 & 60 & $\left(\mathrm{~B}_{3.0} \mathrm{~N}_{3.2} \mathrm{H}_{3.8}\right)\left(\mathrm{NEt}_{2}\right)_{0.51}$ \\
\hline HMD & 4.98:10:30 & 120 & $\left(\mathrm{~B}_{3.0} \mathrm{~N}_{3.0} \mathrm{H}_{3.6}\right)\left[\mathrm{N}\left(\mathrm{SiMe}_{3}\right)\right]_{0.29}$ \\
\hline
\end{tabular}

diethylamine (DEA), dipentylamine (DPA) and hexamethyldisilazane (HMD). ${ }^{11,12}$ For example, as shown in Eqn [6], the DPA-4 polymer was synthesized by reacting polyborazylene with DPA in glyme solution at $75^{\circ} \mathrm{C}$ to give a clear polymeric material in $91 \%$ yield with a $\left(\mathrm{B}_{3.0} \mathrm{~N}_{3.12} \mathrm{H}_{3.9}\right)\left(\mathrm{NPn}_{2}\right)_{0.47}$ composition. Other reaction conditions and compositions are shown in Table 1.

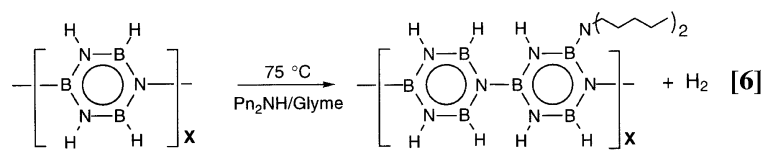

In the case of the DEA- and DPA-modified polymers, spectroscopic studies, model reactions and analysis of volatile by-products indicate that modification of the polymer proceeds primarily through dehydrocoupling. In contrast, modification of the polymer with HMD occurred primarily through N-Si cleavage reactions, as shown in Eqn [7].

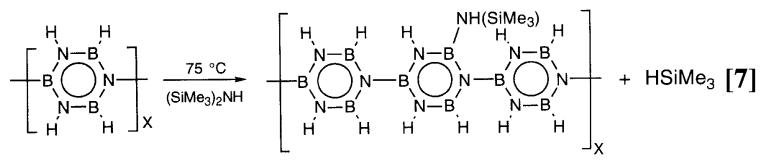

Molecular-weight studies show $M_{\mathrm{n}}=450-800$ for the DEA- and DPA-modified polyborazylenes, compared with $M_{\mathrm{n}}=750$ for the parent polyborazylene. TGA studies of these polymers showed a reduction in low-temperature crosslinking reactions, with the onset of decomposition and weight loss increasing to $\mathrm{ca} 100^{\circ} \mathrm{C}$ (Fig. 1). Because of the introduction of new crosslinking reactions involving the pendant $\mathrm{HN}-\mathrm{SiMe}_{3}$ groups, the HMDmodified polymers showed an increase in molecular weight $\left(M_{\mathrm{n}}=1500\right)$. Likewise, TGA studies showed HMD-modified polymers to undergo further crosslinking reactions at low temperatures.

DSC studies showed that the long-chain alkyl

(C) 1998 John Wiley \& Sons, Ltd. groups of the pendant DPA groups serve as efficient plasticizers, reducing the $T_{\mathrm{g}}$ of the polymer to $90{ }^{\circ} \mathrm{C}$ and making the DPA-modified polymers excellent candidates for melt-spinning. As shown in the scanning electron micrograph in Fig. 2, highquality DPA-4 polymer fibers were achieved by the continuous extrusion of polymer melts to give polymer fibers that are flexible, uniform and free of voids. Pyrolysis of the cured polymer fibers under ammonia to $1000^{\circ} \mathrm{C}$ produced clear, flexible boron nitride fibers of $c a 30 \mu \mathrm{m}$ diameter. SEM micrographs Fig. 3 also show that these ceramic fibers are smooth, uniform and dense. X-ray diffraction studies, on both single ceramic fibers (Fig. 4) and bulk samples, and powder DRIFT spectra are consistent with the formation of turbostratic BN. A typical elemental analysis of a bulk sample is $\mathrm{B}_{1.00} \mathrm{~N}_{1.03} \mathrm{C}_{0.00} \mathrm{H}_{0.20}$, whereas Rutherford backscattering spectrographs of single fibers showed a surface composition of $\mathrm{B}_{1.5} \pm 0 .{ }_{0} \mathrm{~N}_{1.0} \pm 0.2 \mathrm{O}_{0.2} \pm 0.1$ consistent with the formation of a $\mathrm{B}_{2} \mathrm{O}_{3}$ surface species during air-cure of the fibers. Oxidation studies Fig. 5 of crushed DPA-4 derived BN fibers show an onset of oxidation typical of boron nitride.

Preliminary measurements of the mechanical properties of crude $30 \mu \mathrm{m} \mathrm{BN}$ fibers derived from DPA-4 gave typical tensile strengths of $0.18 \mathrm{GPa}$ and elastic moduli of $\mathrm{ca} 14 \mathrm{GPa}$. These values are lower than the poly(aminoborazine)-derived BN fibers reported by Kimura; ${ }^{13,14}$ however, because strengths depend strongly on the fiber diameter and processing parameters, significant increases in the strengths of the DPA-derived BN fibers are expected with the use of a more sophisticated spinning apparatus and higher-temperature sintering.

The DPA-modified polyborazylenes are particularly attractive precursors to $\mathrm{BN}$ fibers since the convenient, high-yield syntheses of the $\left[\mathrm{B}_{3} \mathrm{~N}_{3} \mathrm{H}_{\sim 4}\right]_{x}$ polymer $^{8,9}$ and its precursor, borazine, ${ }^{16}$ provide efficient and economical routes to the polymer. 


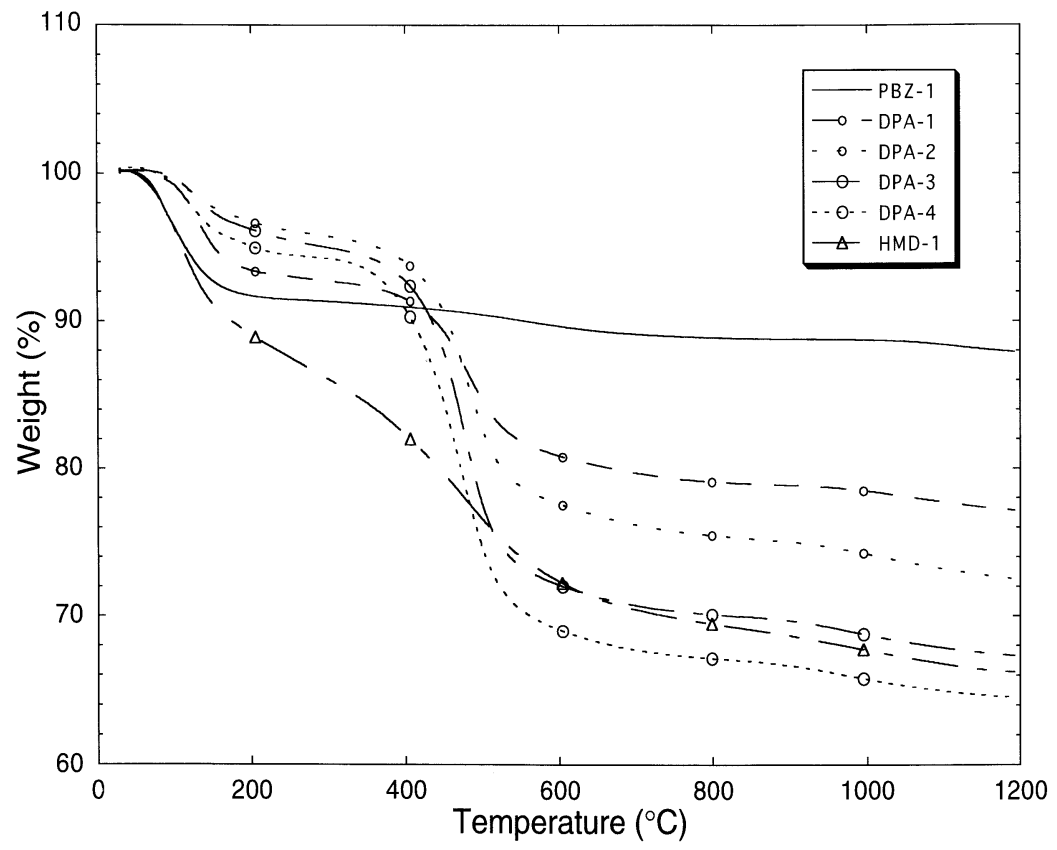

Figure 1 TGA studies of amine-modified polyborazylenes.

Furthermore, it is expected that the properties of the polyborazylene polymer can now be systematically tailored for use in different technological applications by modification with the wide variety of dialkylamines available. For example, the HMD polymers $\left.\left(\left\{\left(\mathrm{R}_{3} \mathrm{Si}\right)_{x} \mathrm{~B}_{3} \mathrm{~N}_{3} \mathrm{H}_{4-x}\right)\right\}_{\mathrm{y}}\right)$ are being investigated as potential precursors to oxidation-resistant BNSi hybrid ceramics.

\section{NEW POLYBOROSILAZANES: PRECURSORS TO SINCB COMPOSITES}

Compared with single-component ceramics, ceramic composites often offer many advantages for high-performance applications. For example, composite SiNCB ceramics have a number of enhanced properties compared with traditional SiNC ceramics, including higher thermal and oxidative stabilities, controllable thermal expansions, decreased crystallinities and higher ceramic and chemical yields. For some recent reviews on the development of polymeric precursors to SiNCB materials, see Refs 17 and 18. Likewise, SiNCB ceramics have been shown to function as self- sealing barriers for the oxidation of carbon in carbon-carbon composites (see, for example, Ref. 19).

It has been our goal to develop new 'singlesource' polyborosilazane precursors that would allow the formation of compositionally homogeneous SiNCB composites in processed forms. Our initial work on first-generation SiNCB precursors focused on borazine-based polyborosilazanes, including both borazine-co-silazane backbone polymers and boron-modified hydridopolysilazanes.

\section{First generation SiNCB precursors: borazine-based polyborosilazanes}

As shown in Scheme 2, borazine-co-silazane backbone copolymers have been obtained by the thermal condensation of borazine with two silazanes, 1,1,3,3,5,5-hexamethylcyclotrisilazane (HCT) and tris(trimethylsilylamino)silane (TTS). ${ }^{20,21}$ The freshly prepared polymers are meltable and readily soluble in ethers. Spectroscopic analyses and molecular-weight-distribution studies suggest both series of copolymers have highly complex, branched structures, with multiple borazineboron to silazane-nitrogen linkages. As seen in 

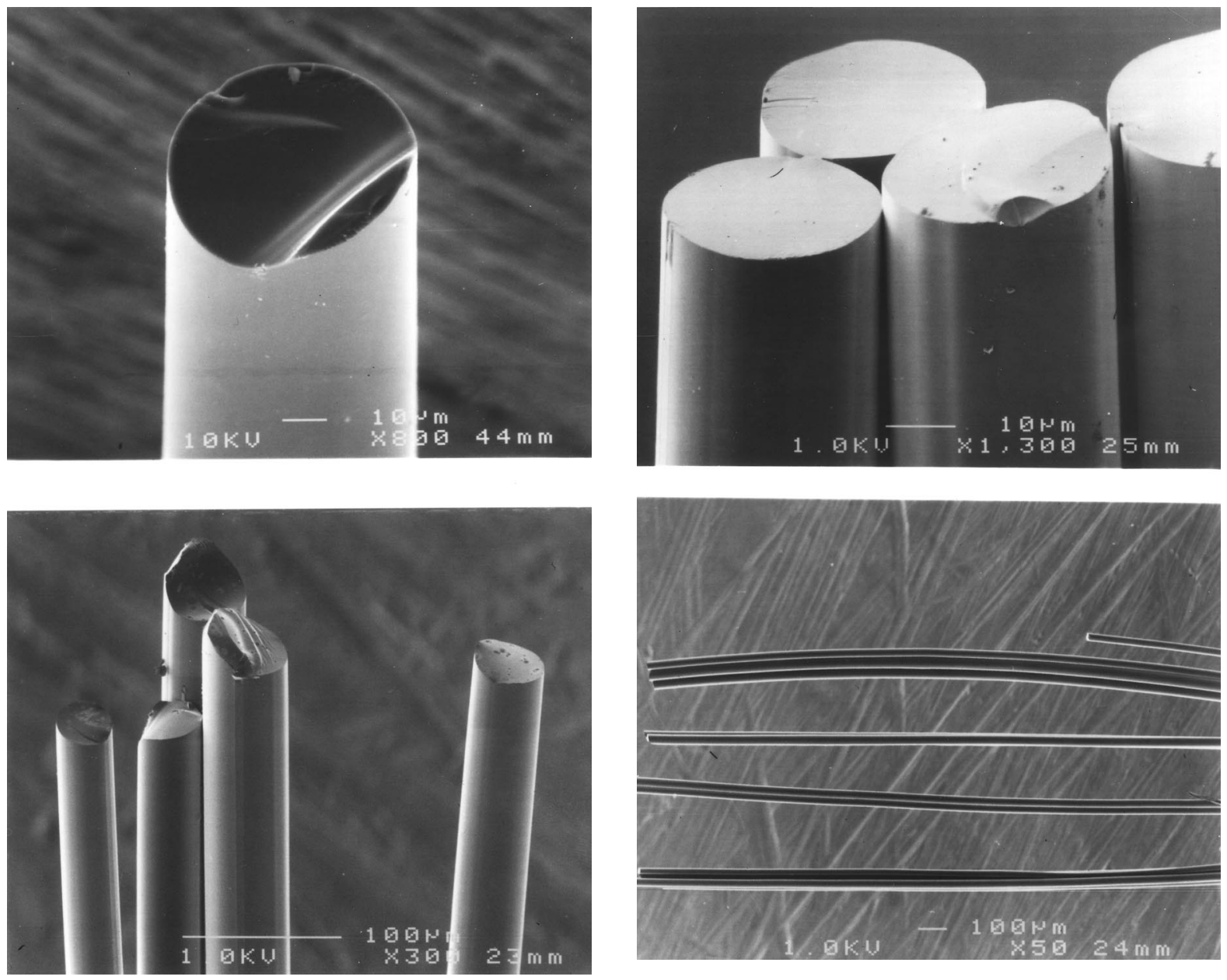

Figure 2 SEM micrographs of DPA-4-derived polymer fibers.

Table 2, elemental analyses of the B-TTS copolymers are consistent with an approximate $\left[\left[\left(-\mathrm{B}_{3} \mathrm{~N}_{3} \mathrm{H}_{4}\right) \mathrm{NH}\right]_{3} \mathrm{SiH}\right]_{x}$ structural unit, while the $\mathrm{B}-\mathrm{HCT}$ copolymers have compositions ranging from $\left(\mathrm{B}_{3} \mathrm{~N}_{3} \mathrm{H}_{4}\right)_{1.00}(\mathrm{~N})_{1.81}\left(\mathrm{SiMe}_{2}\right)_{1.57}(\mathrm{H})_{1.6}$ to $\left(\mathrm{B}_{3} \mathrm{~N}_{3} \mathrm{H}_{4}\right)_{1.00}(\mathrm{~N})_{1.07}\left(\mathrm{SiMe}_{2}\right)_{1.28}(\mathrm{H})_{0.9}$. Molecularweight studies indicate highly branched structures and relatively low molecular weights with $M_{\mathrm{n}}=1000-2000$ for B-TTS and $M_{\mathrm{n}}=3000-4000$ for B-HCT. The polymers also have large polydispersities.

Using an alternative approach involving the modification of a performed polysilazane with a boron-containing pendant, borazine-substituted hydridopolysilazanes were achieved by the reaction of hydridopolysilazane (HPZ) ${ }^{22}$ with liquid borazine at moderate temperatures (Eqn [8]). ${ }^{23,24}$ As shown

Figure 3 SEM micrographs of DPA-4-derived BN ceramic fibers.

in Table 2, the borazine-modified hydridopolysilazanes can be prepared with relatively high molecular weights $\left(M_{\mathrm{n}}=5000-24000\right)$, and a range of boron contents $(2-17 \%)$. The amount of borazine incorporated into the hydridopolysilazane can be readily controlled. For example, polymers of compositions $\left(\mathrm{B}_{3} \mathrm{~N}_{3} \mathrm{H}_{5}\right)_{0.02}(\mathrm{HSi})_{0.30}\left(\mathrm{Me}_{3} \mathrm{Si}\right)_{0.19}$ $(\mathrm{NH})_{0.26} \quad \mathrm{~N}_{0.23}$ and $\left(\mathrm{B}_{3} \mathrm{~N}_{3} \mathrm{H}_{5}\right)_{0.07} \quad(\mathrm{HSi})_{0.34}$ $\left(\mathrm{Me}_{3} \mathrm{Si}\right)_{0.18}(\mathrm{NH})_{0.13} \mathrm{~N}_{0.28}$ were prepared by heating $\mathrm{HPZ}$ in excess borazine at $73^{\circ} \mathrm{C}$ for 2.2 and $7.0 \mathrm{~h}$, respectively. The spectroscopic data for the new polymers indicate that they have retained their hydridopolysilazane backbones and are substituted with pendant borazines by means of a borazineboron to polymer-nitrogen linkage. Such linkages may have formed by either hydrogen or trimethylsilane elimination reactions.

(C) 1998 John Wiley \& Sons, Ltd. 


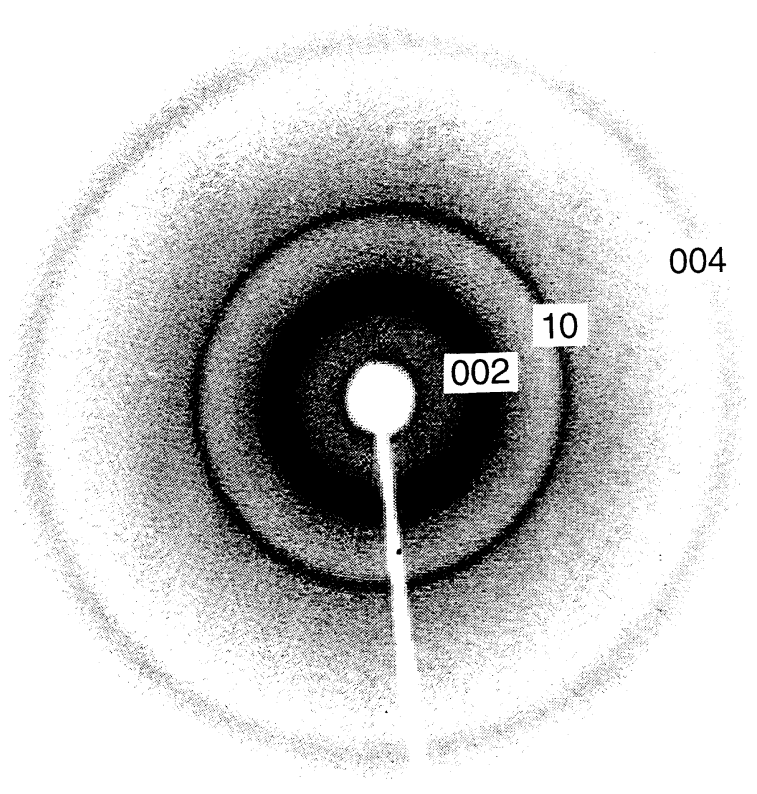

Figure 4 X-ray diffraction spectrum of a single DPA-4derived $\mathrm{BN}$ ceramic fiber.

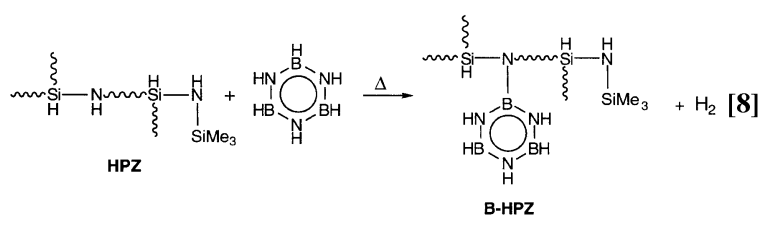

Studies of the ceramic conversions reactions of the three borazine-modified polymers B-HCT, B-
$\mathrm{TTS}^{20,21}$ and $\mathrm{B}-\mathrm{HPZ}^{23,24}$ ) demonstrated that they are each converted to composite SiNCB ceramic materials in high ceramic and chemical yields, but that each polymer system has its own unique properties. As shown in Tables 3 and 4, the two copolymer systems yield ceramics having much higher boron contents than the higher-molecular weight B-HPZ polymers. Furthermore, even with the similarities in their polymer elemental compositions, structural differences in the two copolymer systems result in different ceramic compositions upon pyrolysis. Whereas the B-HCT copolymers are converted to $\mathrm{SiNCB}$ ceramic materials with retention of $\mathrm{Si}$ and $\mathrm{C}$ to $1800{ }^{\circ} \mathrm{C}$, the facile loss of $-\mathrm{SiMe}_{3}$ groups from the B-TTS-based ceramics yields low-carbon SiNB ceramics at $1400^{\circ} \mathrm{C}$. Further loss of Si from the B-TTS-based ceramics produces dense $\mathrm{BN}$-rich materials at $1800^{\circ} \mathrm{C}$. The higher-molecular-weight B-HPZ-2 polymers, however, yield lower-boron-content SiNCB ceramics with typical compositions at $1400{ }^{\circ} \mathrm{C}$ of $\mathrm{Si}_{1.00} \mathrm{~B}_{0.09} \mathrm{~N}_{1.08} \mathrm{C}_{0.44}$. At $1800{ }^{\circ} \mathrm{C}$, the B-HPZ-2derived ceramics still retain nitrogen efficiently, with typical compositions of $\mathrm{Si}_{1.00} \mathrm{~B}_{0.10} \mathrm{~N}_{0.47} \mathrm{C}_{0.58}$. In contrast, the ceramics derived from unmodified HPZ are unstable to nitrogen loss, and are nearly pure $\mathrm{SiC}$ at $1800{ }^{\circ} \mathrm{C}$, with typical compositions of $\mathrm{Si}_{1.00} \mathrm{C}_{0.92} \mathrm{~N}_{<0.03}$ (Tables 3 and 4). ${ }^{22,23,24}$

X-ray diffraction (XRD) studies of the ceramics obtained from all three types of borazine-based polymers showed they are largely amorphous to $1400{ }^{\circ} \mathrm{C}$. At $1800{ }^{\circ} \mathrm{C}$, crystallization of $\beta-\mathrm{Si}_{3} \mathrm{~N}_{4}, \beta$ $\mathrm{SiC}$ and elemental $\mathrm{Si}$ begins (Fig. 6). Although

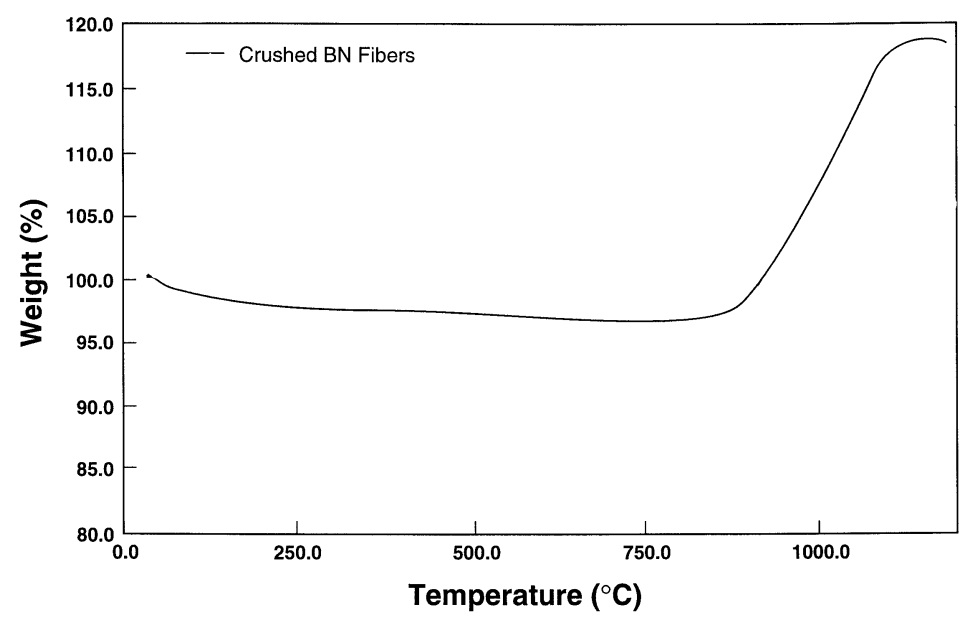

Figure 5 TGA analysis of the oxidation of crushed DPA-4-derived BN fibers under air at $5^{\circ} \mathrm{C} \mathrm{min}^{-1}$. 
Table 2 Polyborosilazane synthesis and composition

\begin{tabular}{|c|c|c|c|c|c|}
\hline Polymer & $\begin{array}{c}\text { Silazane/Borane } \\
(\mathrm{g}: \mathrm{g})\end{array}$ & $\begin{array}{c}\text { Time }(\mathrm{h}) / \text { Temp } \\
\left({ }^{\circ} \mathrm{C}\right)\end{array}$ & $T_{\mathrm{g}}\left({ }^{\circ} \mathrm{C}\right)$ & Composition & $M_{\mathrm{n}}\left(\mathrm{g} \mathrm{mol}^{-1}\right)$ \\
\hline B-TTS & $3.30: 5.90$ & $210 / 90$ & - & $\left(\mathrm{B}_{3} \mathrm{~N}_{3} \mathrm{H}_{4}\right)_{1.00}(\mathrm{~N})_{1.17}\left(\mathrm{SiMe}_{3}\right)_{1.16}(\mathrm{SiH})_{0.34}$ & 1356 \\
\hline B-HCT & $3.43: 4.61$ & 120 & - & $\left(\mathrm{B}_{3} \mathrm{~N}_{3} \mathrm{H}_{4}\right)_{1.00}(\mathrm{~N})_{1.67}\left(\mathrm{SiMe}_{2}\right)_{1.49}(\mathrm{H})_{1.5}$ & 3201 \\
\hline HPZ & - & - & 87.0 & $\mathrm{Si}_{1.00} \mathrm{~N}_{1.04} \mathrm{C}_{1.16} \mathrm{H}_{4.69}$ & 25800 \\
\hline B-HPZ-1 & $5.16: 8.00$ & $2.2 / 65$ & - & $\mathrm{Si}_{1.00} \mathrm{~N}_{0.77} \mathrm{C}_{1.09} \mathrm{H}_{4.44}\left(\mathrm{~B}_{3} \mathrm{~N}_{3} \mathrm{H}_{5}\right)_{0.025}$ & 24000 \\
\hline B-HPZ-2 & 26.00:21.68 & $2.2 / 73$ & - & $\mathrm{Si}_{1.00} \mathrm{~N}_{0.99} \mathrm{C}_{1.17} \mathrm{H}_{4.61}\left(\mathrm{~B}_{3} \mathrm{~N}_{3} \mathrm{H}_{5}\right)_{0.045}$ & 23300 \\
\hline B-HPZ-3 & $1.52: 3.24$ & $7.0 / 73$ & - & $\mathrm{Si}_{1.00} \mathrm{~N}_{0.79} \mathrm{C}_{1.02} \mathrm{H}_{3.93}\left(\mathrm{~B}_{3} \mathrm{~N}_{3} \mathrm{H}_{5}\right)_{0.14}$ & 13300 \\
\hline B-HPZ-4 & $1.51: 3.15$ & $17.5 / 73$ & - & $\mathrm{Si}_{1.00} \mathrm{~N}_{0.94} \mathrm{C}_{1.04} \mathrm{H}_{3.41}\left(\mathrm{~B}_{3} \mathrm{~N}_{3} \mathrm{H}_{5}\right)_{0.56}$ & 5492 \\
\hline PIN-HPZ-1 & 7.99:7.98 & $2 / 60$ & 120.9 & $\mathrm{Si}_{1.00} \mathrm{~N}_{0.96} \mathrm{C}_{1.00} \mathrm{H}_{4.25}\left(\mathrm{C}_{6} \mathrm{H}_{12} \mathrm{BO}_{2}\right)_{0.06}$ & 6110 \\
\hline PIN-HPZ-2 & 7.98:8.00 & $8 / 60$ & 110.9 & $\mathrm{Si}_{1.00} \mathrm{~N}_{0.87} \mathrm{C}_{0.83} \mathrm{H}_{4.01}\left(\mathrm{C}_{6} \mathrm{H}_{12} \mathrm{BO}_{2}\right)_{0.13}$ & 2655 \\
\hline PIN-HPZ-3 & 8.00:7.99 & $24 / 60$ & 102.3 & $\mathrm{Si}_{1.00} \mathrm{~N}_{0.90} \mathrm{C}_{0.86} \mathrm{H}_{3.93}\left(\mathrm{C}_{6} \mathrm{H}_{12} \mathrm{BO}_{2}\right)_{0.18}$ & 2205 \\
\hline DEB-HPZ-1 & $6.60: 6.67$ & $8 / 100$ & 78.3 & $\mathrm{Si}_{1.00} \mathrm{~N}_{0.73} \mathrm{C}_{1.04} \mathrm{H}_{4.18}\left(\mathrm{C}_{4} \mathrm{H}_{13} \mathrm{~B}_{3} \mathrm{~N}_{3}\right)_{0.07}$ & 3710 \\
\hline DEB-HPZ-2 & 7.96:8.00 & $24 / 100$ & 49.7 & $\mathrm{Si}_{1.00} \mathrm{~N}_{0.84} \mathrm{C}_{1.04} \mathrm{H}_{4.25}\left(\mathrm{C}_{4} \mathrm{H}_{13} \mathrm{~B}_{3} \mathrm{~N}_{3}\right)_{0.18}$ & 3260 \\
\hline DEB-HPZ-3 & $7.50: 7.63$ & $70 / 100$ & 23.0 & $\mathrm{Si}_{1.00} \mathrm{~N}_{0.76} \mathrm{C}_{0.94} \mathrm{H}_{4.29}\left(\mathrm{C}_{4} \mathrm{H}_{13} \mathrm{~B}_{3} \mathrm{~N}_{3}\right)_{0.35}$ & 2730 \\
\hline
\end{tabular}

DRIFT spectra show strong absorptions characteristic of boron nitride, no crystalline boron-containing phases are observed to $1800{ }^{\circ} \mathrm{C}$. In contrast, initial crystallization of $\alpha-\mathrm{Si}_{3} \mathrm{~N}_{4}$ in polysilazane-derived ceramics, such as HPZ ceramics, is usually observed near $1400^{\circ} \mathrm{C}$. Above $1600{ }^{\circ} \mathrm{C}$, the ceramics begin to decompose with loss of nitrogen, and both $\alpha-\mathrm{Si}_{3} \mathrm{~N}_{4}$ and $\beta$-SiC crystallize. By $1800^{\circ} \mathrm{C}$, nitrogen loss is complete and only crystalline $\beta$-SiC is usually observed by XRD.

The addition of boron to the silazane systems serves both to inhibit crystallization and to improve the thermal stability of the silicon-based ceramics. The differences in the composition of the ceramics derived from these systems allow for significantly different potential applications. Whereas the BHCT based ceramics could serve as effective precursors to high-BN SiNCB ceramic matrix materials, the efficient elimination of both $\mathrm{Si}$ and $\mathrm{C}$ from the B-TTS-based copolymers suggests that they may be better suited as precursors for amorphous $\mathrm{BN}$ coatings on carbon and/or ceramic fibers. The B-HPZ polymers serve as excellent higher-molecular-weight precursors to lowerboron-content SiNCB ceramics.

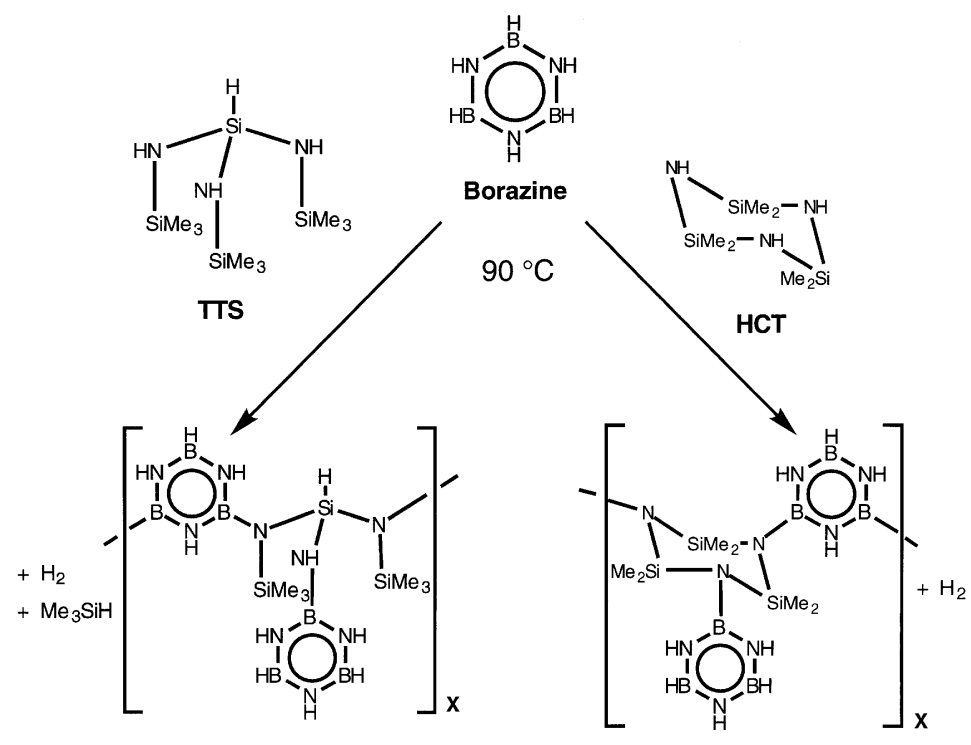

Scheme 2 Synthesis and possible structures of borazine-silazane copolymers. 
Table 3 Polyborosilazane-derived ceramic compositions at $1400{ }^{\circ} \mathrm{C}$

\begin{tabular}{lccc}
\hline Polymer & $\begin{array}{c}\text { Bulk ceramic conversion } \\
(\mathrm{wt} \%)\end{array}$ & Composition & Density $\left(\mathrm{g} / \mathrm{ml}^{-1}\right)$ \\
\hline B-TTS & 37.8 & $\mathrm{Si}_{1.00} \mathrm{~N}_{5.52} \mathrm{C}_{0.21} \mathrm{~B}_{5.26}$ & 1.7 \\
B-HCT & 54.3 & $\mathrm{Si}_{1.00} \mathrm{~N}_{3.89} \mathrm{C}_{0.64} \mathrm{~B}_{2.78}$ & 1.7 \\
B-HPZ-2 & 70.0 & $\mathrm{Si}_{1.00} \mathrm{~N}_{1.08} \mathrm{C}_{0.44} \mathrm{~B}_{0.09}$ & 2.3 \\
PIN-HPZ-3 & 59.1 & $\mathrm{Si}_{1.00} \mathrm{~N}_{1.02} \mathrm{C}_{0.67} \mathrm{~B}_{0.15} \mathrm{O}_{0.26}$ & 2.3 \\
HPZ & 57.0 & $\mathrm{Si}_{1.00} \mathrm{~N}_{0.97} \mathrm{C}_{0.41}$ & 2.6 \\
\hline
\end{tabular}

Table 4 Polyborosilazane-derived ceramic compositions at $1800^{\circ} \mathrm{C}$

\begin{tabular}{lccc}
\hline Polymer & $\begin{array}{c}\text { Bulk ceramic conversion } \\
(\mathrm{wt} \%)\end{array}$ & Composition & Density $\left(\mathrm{g} / \mathrm{ml}^{-1}\right)$ \\
\hline B-TTS & 26.1 & $\mathrm{~B}_{1.00} \mathrm{~N}_{0.86} \mathrm{C}_{<0.01} \mathrm{Si}_{1.01}$ & 2.3 \\
B-HCT & 36.2 & $\mathrm{Si}_{1.00} \mathrm{~N}_{2.81} \mathrm{C}_{0.73} \mathrm{~B}_{2.70}$ & 2.0 \\
B-HPZ-2 & 51.1 & $\mathrm{Si}_{1.00} \mathrm{~N}_{0.47} \mathrm{C}_{0.58} \mathrm{~B}_{0.10}$ & -1.45 \\
PIN-HPZ-3 & 53.7 & $\mathrm{Si}_{1.00} \mathrm{~N}_{0.91} \mathrm{C}_{0.68} \mathrm{~B}_{0.18} \mathrm{O}_{0.28}$ & - \\
HPZ & 42.4 & $\mathrm{Si}_{1.00} \mathrm{~N}_{0.03} \mathrm{C}_{0.94}$ & \\
\hline
\end{tabular}

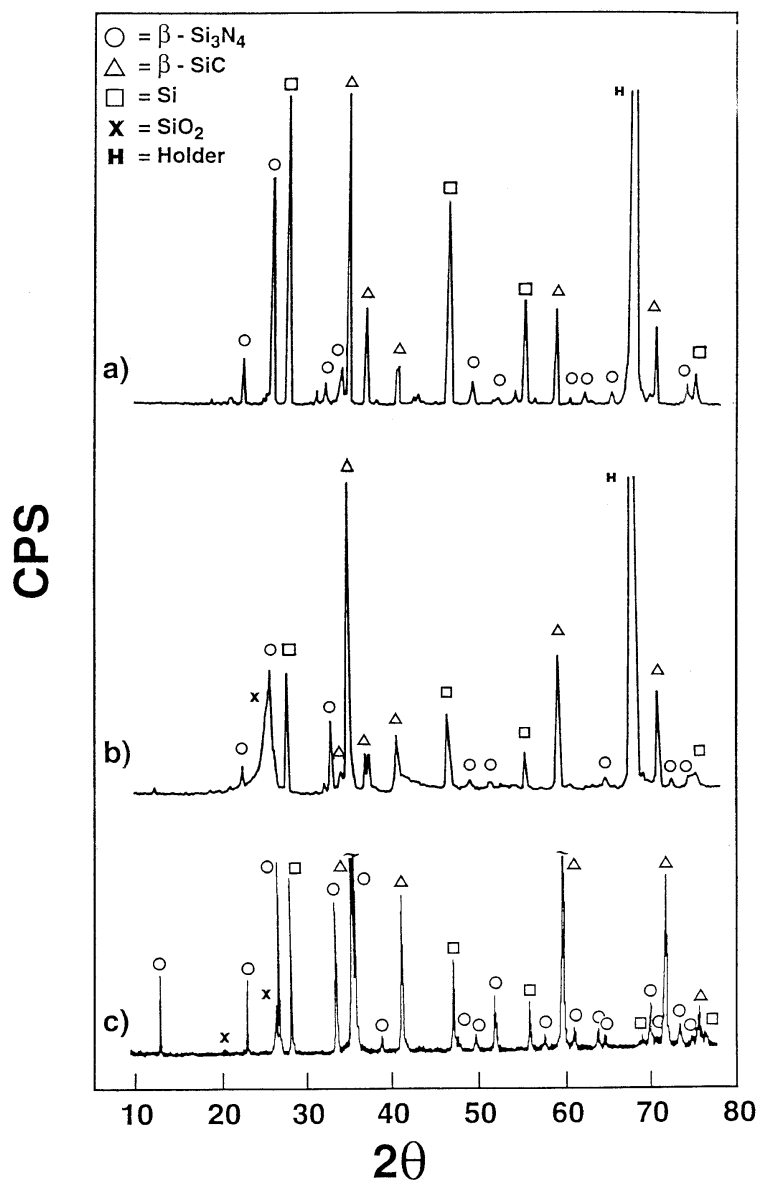

Figure 6 Powder $\mathrm{X}$-ray diffraction spectra of the ceramics derived from pyrolysis at $1800^{\circ} \mathrm{C}$ of (a) B-TTS, (b) B-HCT and (c) B-HPZ-2 polymers.

\section{Second-generation SiNCB precursors}

Whereas the B-TTS, B-HCT and B-HPZ polymers may prove to be suitable precursors to $\mathrm{SiNCB}$ matrix materials and/or coatings, many other potential applications will require much greater control of structure and reactivity than is at present available in these systems. Because of the latent reactivity of the $\mathrm{B}-\mathrm{H}$ groups on the pendant borazinyl rings, these polymers continue to react and build molecular weight in their melts by the crosslinking reaction illustrated in Scheme 3. These polymers are therefore not suitable for processes that require stable melt viscosities, e.g., in the generation of polymer fibers by melt-spinning.

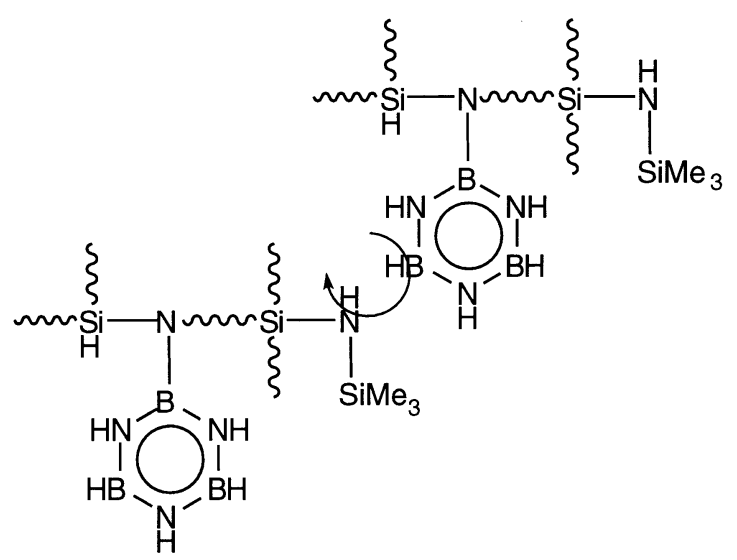

Scheme 3 Low-temperature crosslinking reactions of B-HPZ polymers. 
<smiles>CC1OB(P)O1</smiles>

PIN<smiles>CCB1NBBNB(CC)N1</smiles>

DEB

Figure 7 Monofunctional boranes: pinacolborane (PIN), and $B$-diethylborazine (DEB).

As in the case of the polyborazylene polymers, the key step needed to retard the crosslinking reaction of the polyborosilazane polymers is to remove or block any reactive $\mathrm{B}-\mathrm{H}$ groups. With this aim in mind we have now investigated the design of new second-generation hydridopolysilazanes derived from monofunctional boranes (Eqn [9]). ${ }^{25}$ Since these new borane-modified polymers do not contain reactive $\mathrm{B}-\mathrm{H}$ groups, they cannot undergo the crosslinking reactions occurring in the borazine-based polymers.

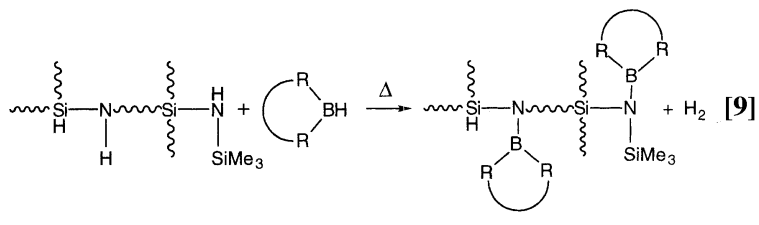

Our initial studies with borane reagents such as 9-borabicyclo-[3,3.1]nonane (9-BBN) and catecholborane demonstrated that these monofunctional

boranes are not sufficiently stable to achieve a processable polymer. However, as shown in Fig. 7 we have now identified several different monofunctional boranes, including pinacolborane and $B$ diethylborazine, which are both reactive with HPZ and thermally stable at the temperatures needed for melt-processing. Pinacolborane, which is unique among the $\mathrm{O}-\mathrm{B}-\mathrm{O}$ heterocycles in that it is not prone to disproportionation, is commercially available or can be prepared from the reaction of $\mathrm{BH}_{3}$. THF with pinacol. $B$-Diethylborazine can be obtained readily on a large scale via the rhodiumcatalyzed borazine/ethylene reaction. ${ }^{10}$

As summarized in Table 2, boron-modified polymers, PIN-HPZ and DEB-HPZ, were readily prepared by heating solutions of HPZ dissolved in each borane at $60-100^{\circ} \mathrm{C}$. For example, in a typical preparation of PIN-HPZ-3, a $8.00 \mathrm{~g}$ (90.4 mmol of $\mathrm{N}-\mathrm{H}$ sites) sample of $\mathrm{HPZ}$ dissolved in $7.99 \mathrm{~g}$ $(62.5 \mathrm{mmol})$ of PIN-H was heated at $60^{\circ} \mathrm{C}$ for $24 \mathrm{~h}$. After vacuum evaporation of the volatile materials, the modified polymer was removed from the reaction vessel under an inert atmosphere and isolated as a clear, colorless solid. Elemental analysis of PIN-HPZ-3 is consistent with an $(\mathrm{HSi})_{0.33}\left(\mathrm{Me}_{3} \mathrm{Si}\right)_{0.15}(\mathrm{NH})_{0.24} \mathrm{~N}_{0.13}(\mathrm{PIN})_{0.09} \mathrm{com}-$ position. The DEB-HPZ polymers were prepared in a similar fashion, but required longer reaction times (up to 29 days), and higher temperatures $\left(100{ }^{\circ} \mathrm{C}\right)$. Both polymer systems were soluble in common organic solvents, including ethers and hydrocarbons.

The degree of modification can be easily

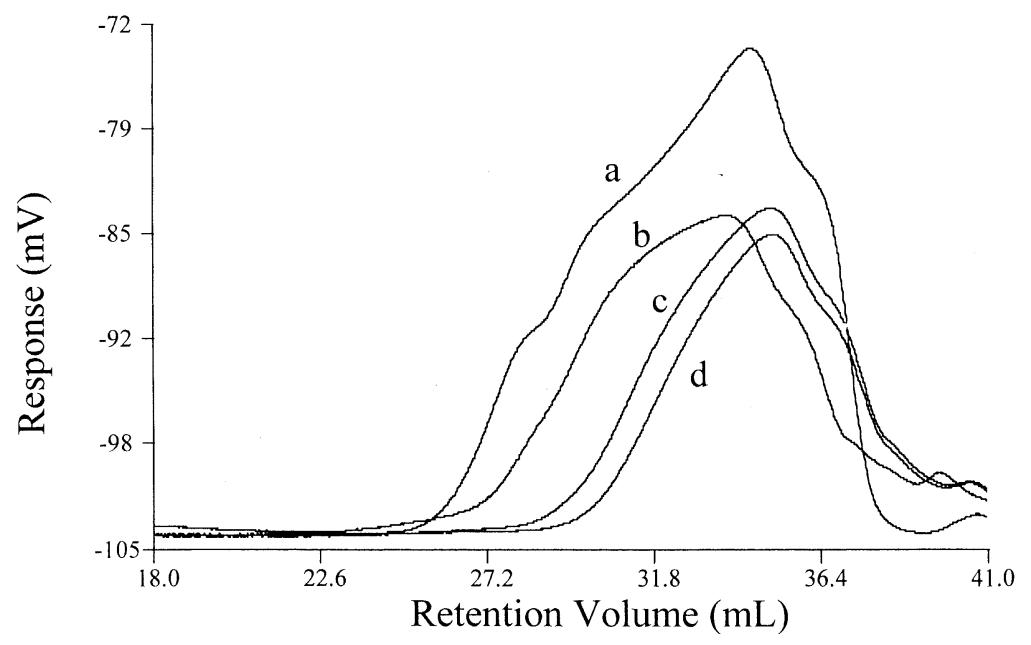

Figure 8 DRI chromatograms of (a) HPZ, (b) PIN-HPZ-1, (c) PIN-HPZ-2 and (d) PIN-HPZ-3. 


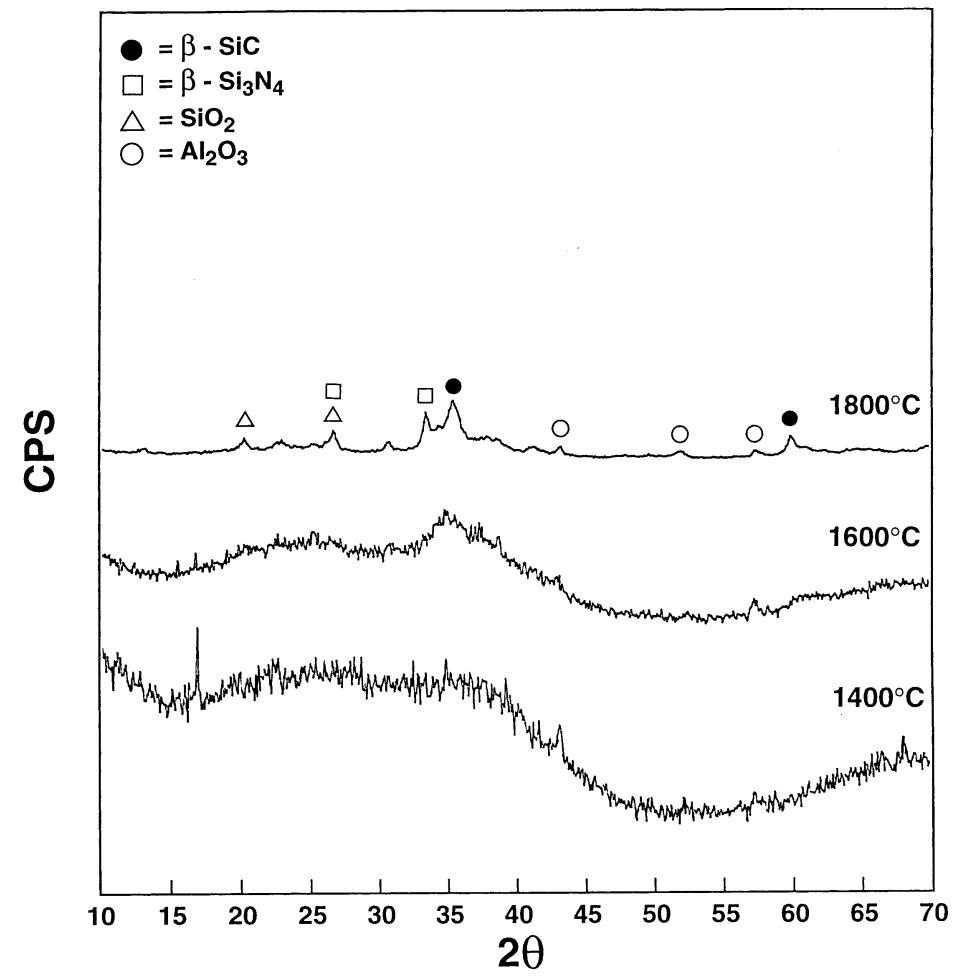

Figure 9 Powder XRD spectra of PIN-HPZ-3 pyrolyzed to (a) $1400{ }^{\circ} \mathrm{C}$, (b) $1600{ }^{\circ} \mathrm{C}$ and (c) $1800{ }^{\circ} \mathrm{C}$. (The $\mathrm{Al}_{2} \mathrm{O}_{3}$ impurity comes from the pestle and mortar used to grind the sample.)

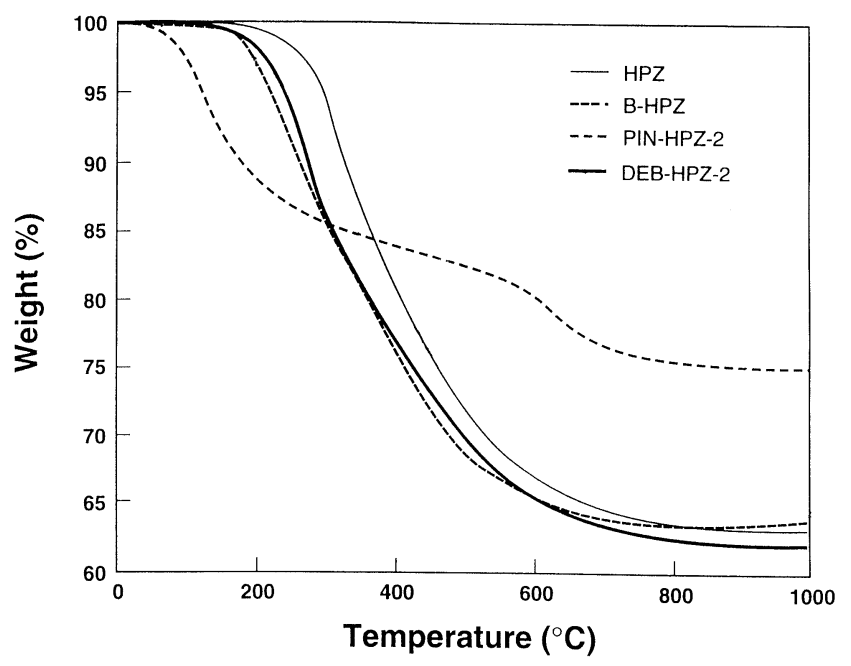

Figure 10 TGA studies of HPZ, B-HPZ, PIN-HPZ-3 and DEB-HPZ.

controlled by the duration of the reaction, with typical boron content $\mathrm{ca} 1-3 \%$. Increases in the boron content were accompanied by stoichiometric increases in the carbon and hydrogen contents owing to the alkyl groups on the borane rings. In addition, the DEB-HPZ polymers showed the expected increase in nitrogen content owing to the borane ring nitrogens. Oxygen content, as deter- 

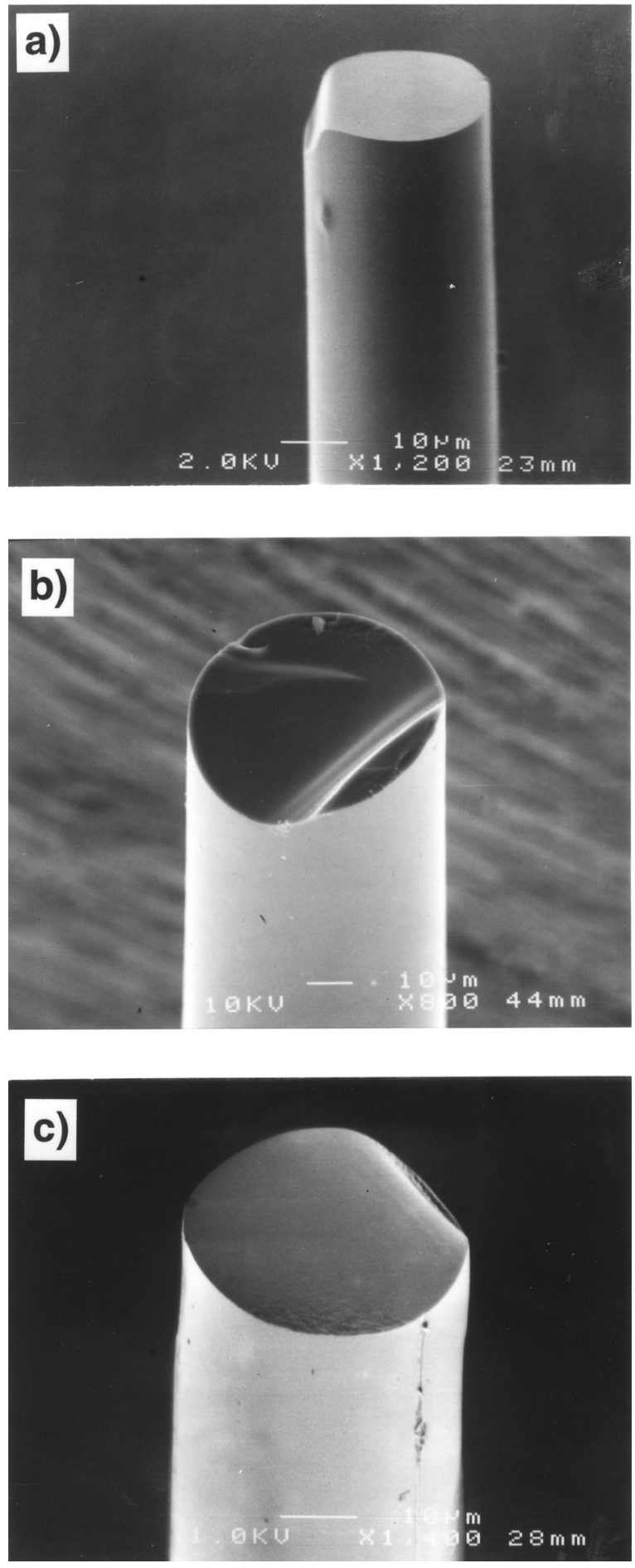

Figure 11 Scanning electron micrographs of (a) polymer fiber derived from PIN-HPZ-3, (b) polymer fiber derived from DEB-HPZ and (c) ceramic fiber derived from the $1200^{\circ} \mathrm{C}$ pyrolysis of PIN-HPZ-3.

(C) 1998 John Wiley \& Sons, Ltd. mined by difference, paralleled changes in boron content in the PIN-HPZ polymers.

In each system, hydrogen was evolved in a molar ratio of almost 1:1, with the amount of incorporated borane suggesting that dehydrocoupling is the dominant means of modification. Spectroscopic studies, model reactions and analysis of the volatile by-products suggest, as was proposed ${ }^{23,24}$ for the B-HPZ polymer, that borane modification of the polymer occurs via the creation of $\mathrm{B}-\mathrm{N}$ linkages. SEC/DRI chromatograms for HPZ and modified HPZ were typically multimodal, indicating heterogeneous chain/cage structures and/or compositional heterogeneity (Fig. 8). As can be seen in both Fig. 8 and Table 2, increasing functionalization decreased polymer weight, suggesting chain degradations.

Studies of the conversions of polymer to ceramic showed that the modified polymers yield SiNCB ceramics containing approximately $1-3 \%$ boron at $1400{ }^{\circ} \mathrm{C}$, with the highest boron content in the PINHPZ-derived samples Table 3. At $1800{ }^{\circ} \mathrm{C}$, the PIN-HPZ-derived ceramics exhibited improved thermal stability with nitrogen contents of up to $23 \%$, compared with the ceramics obtained from unmodified HPZ, which usually retain less than $4 \%$ nitrogen at this temperature (Table 4). Furthermore, while the DEB-HPZ-derived ceramics showed crystallization properties similar to the ceramic obtained from unmodified HPZ, the PIN-HPZ-3derived ceramics were amorphous to $1600{ }^{\circ} \mathrm{C}$, and at $1800{ }^{\circ} \mathrm{C}$ showed only weak diffraction from $\beta$ SiC (Fig. 9). Thus, the higher-boron-content PINHPZ-based ceramics have properties equivalent to or better than those obtained from the B-HPZ polymer. However, unlike the B-HPZ polymers, which show initial weight losses due to crosslinking below $80^{\circ} \mathrm{C},{ }^{23,24}$ TGA studies (Fig. 10) of the PINHPZ and DEB-HPZ samples showed a broad weight loss over the $200-800{ }^{\circ} \mathrm{C}$ temperature range, very similar to that of the parent HPZ. TGA-MS analyses of the volatiles evolved during pyrolysis showed no differences between the modified and unmodified polymers. Clearly, the crosslinking reaction that results in the low-temperature weight loss in the B-HPZ polymers has been suppressed in the PIN-HPZ and DEB-HPZ polymers.

With a $T_{\mathrm{g}}$ of $87^{\circ} \mathrm{C}$ and an onset of weight loss at ca $200{ }^{\circ} \mathrm{C}$, the parent HPZ polymer has excellent rheology for melt-spinning. As seen in Table 2, thermal mechanical analyses (TMAs) of the PINHPZ and DEB-HPZ polymers showed only slight changes in the $T_{\mathrm{g}}$ with modification. Most importantly, in contrast to the B-HPZ polymers, the PIN-HPZ and DEB-HPZ polymers were found to 
be stable as melts, and thus be excellent candidates for melt-spinning. Using a crude ram extruder it was then possible to extrude approx. $30-40 \mu \mathrm{m}$ polymer fibers continuously at a rate of $c a 60 \mathrm{~m}$ min. ${ }^{-1}$ Scanning electron micrographs of the PINHPZ-3 polymer fibers show that they are smooth and uniform (Fig. 11a). After a brief cure with $\mathrm{Cl}_{3} \mathrm{SiH}$, pyrolysis under an argon atmosphere to $1200{ }^{\circ} \mathrm{C}$ produced black SiNCB ceramic fibers (Fig. 11c). The ceramic fibers were dense and relatively uniform but, because of the defects induced by the crude spinning conditions, they were found to be too weak for mechanical testing. With the use of a more sophisticated spinning apparatus and curing procedures it should be possible to generate fibers with enhanced mechanical properties. These studies are in progress.

\section{CONCLUSIONS}

The work described above has demonstrated a viable design strategy for the formation of meltable polymeric precursors to both boron nitride and SiNCB ceramics based on the controlled functionalization of preformed polymers with pendant groups of suitable compositions and crosslinking properties. Both the dipentylamine-polyborazylene (DPA) and pinacolborane-hydridopolysilazane (PIN-HPZ) polymers, unlike the parent polyborazylene (PB) and the borazine-hydridopolysilazane polymers (B-HPZ), are stable as melts and can be easily melt-spun into polymer fibers. Subsequent pyrolyses of these polymer fibers then provide excellent routes to $\mathrm{BN}$ and $\mathrm{SiNCB}$ ceramic fibers. The ease of synthesis of both polymer systems suggests that new hybrid polymers with a range of substituents appended to the polyborazylene or hydridopolysilazane backbones should now be readily achieved, allowing even greater control over polymer and ceramic properties.

Acknowledgments We thank the US Department of Energy, Division of Chemical Sciences, the Office of Basic Energy Sciences, the Office of Energy Research and the National Science Foundation for their support of this research.

\section{REFERENCES}

1. K. J. Wynne and R. Rice, Annu. Rev. Mater. Sci. 14, 297 (1984).

C) 1998 John Wiley \& Sons, Ltd.
2. R. T. Paine and C. K. Narula, Chem. Rev. 90, 73 (1990) and references therein.

3. A. Meller, Gmelin Handbuch der Anorganische Chemie, Boron Compounds, Springer-Verlag, Berlin, 1983, 2nd Supplement, Vol. 1.

4. A. Meller, Gmelin Handbuch der Anorganische Chemie, Boron Compounds, Springer-Verlag, Berlin, 1988, 3rd Supplement, Vol. 3, and references therein.

5. P. Bracke, H. Schurmans and J. Verhoest, Inorganic Fibres and Composite Materials: A Survey of Recent Developments, Pergamon, New York, 1984, p. 54, and references therein.

6. K. Nakamura, in: Synthesis and Properties of Boron Nitride, Pouch, J. J. and Alterovitz, S. A. (eds), Trans. Tech., Brookfield, 1990, pp. 111-140.

7. N. N. Geenwood and A. Earnshaw, in: Chemistry of the Elements, Pergamon Press, New York, 1994.

8. P. J. Fazen, E. E. Remsen, P. J. Carroll, J. S. Beck and L. G. Sneddon, Chem. Mater. 7, 1942 (1995).

9. P. J. Fazen, J. S. Beck, A. T. Lynch, E. E. Remsen and L. G. Sneddon, Chem. Mater. 2, 96 (1990).

10. P. J. Fazen and L. G. Sneddon, Organometallics 13, 2867 (1994).

11. T. Wideman and L. G. Sneddon, Chem. Mater. 8, 3 (1996).

12. T. Wideman, E. E. Remsen, E. Cortez, V. L. Chlanda and L. G. Sneddon, Chem. Mater. 10, 412 (1998).

13. Y. Kimura, Y. Kubo and N. Hayashi, Comp. Sci. Tech. 51, 173 (1994).

14. Y. Kimura and Y. Kubo, in: Inorganic and Organometallic Polymers II: Advanced Materials and Intermediates, Wisian-Neilson, P., Allcock, H. R. and Wynne, K. J. (eds), ACS Symp. Series No. 572, American Chemical Society, Washington, DC, 1993, pp. 375-388.

15. Y. Kimura, Y. Kubo and N. Hayashi, J. Inorg. Organomeal. Polymer 2, 231 (1992).

16. T. Wideman and L. G. Sneddon, Inorg. Chem. 34, 1002 (1995).

17. J. Bill and F. Aldinger, Z. Metallkunde 11, 827 (1996).

18. H.-P. Baldus and M. Jansen, Angew. Chem., Int. Ed. Engl. 36, 328 (1997) and references therein.

19. H. P. Baldus and G. Passing, Mater. Res. Soc. Symp. Proc. 346, 617 (1994).

20. T. Wideman, K. Su, E. E. Remsen, G. A. Zank and L. G. Sneddon, Chem. Mater. 7, 2203 (1995).

21. T. Wideman, K. Su, E. E. Remsen, G. A. Zank and L. G. Sneddon, Mater. Res. Soc. Proc. 410, 185 (1996).

22. G. E. Legrow, T. F. Lim, J. Lipowitz and R. S. Reaoch, Am. Ceram. Soc. Bull. 66, 363 (1987).

23. K. Su, E. E. Remsen, G. A. Zank and L. G. Sneddon, Chem. Mater. 5, 547 (1993).

24. K. Su, E. E. Remsen, G. A. Zank and L. G. Sneddon, Polym. Prepr. 34, 334 (1993).

25. T. Wideman, E. Cortez, E. E. Remsen, G. A. Zank, P. J Carroll and L. G. Sneddon, Chem. Mater. 9, 2218 (1997).

Appl. Organometal. Chem. 12, 681-693 (1998) 